\title{
The Effect of Rotor Blade Thickness and Surface Finish on the Performance of a Small Axial Flow Turbine
}

Richard J. Roelke

National Aeronautics and Space Administration

Lewis Research Center

and

Jeffrey E. Haas

Propulsion Laboratory

AVRADCOM Research and Technology Laboratories

Lewis Research Center

\section{LIBRARY COPY}

FEB 31982

Work performed for

U.S. DEPARTMENT OF ENERGY

Conservation and Renewable Energy Office of Vehicle and Engine R\&D
Prepared for

1982 Gas Turbine Annual Meeting sponsored by

American Society of Mechanical Engineers

London, England, April 18-22, 1982 


\section{NOTICE}

This report was prepared to document work sponsored by the United States Government. Neither the United States nor its agent, the United States Department of Energy, nor any Federal employees, nor any of their contractors, subcontractors or their employees, makes any warranty, express or implied, or assumes any legal liability or responsibility for the accuracy, completeness, or usefulness of any information, apparatus, product or process disclosed, or represents that its use would not infringe privately owned rights 
DOE/NASA $51040-34$

NASA TM-82726

TR-81-C-29

\section{The Effect of Rotor Blade Thickness and Surface Finish on the Performance of a Small Axial Flow Turbine}

Richard J. Roelke

National Aeronautics and Space Administration

Lewis Research Center

Cleveland, Ohio 44135

and

Jeffrey E. Haas

Propulsion Laboratory

AVRADCOM Research and Technology Laboratories

Lewis Research Center

Cleveland, Ohio 44135

Work performed for

U.S. DEPARTMENT OF ENERGY

Conservation and Renewable Energy

Office of Vehicle and Engine R\&D

Washington, D.C. 20545

Under Interagency Agreement DE-AI01-77CS51040

1982 Gas Turbine Annual Meeting sponsored by American Society of Mechanical Engineers London, England, April 18-22, 1982 
THE EFFECT OF ROTOR BLADE THICKNESS AND SURFACE FINISH

ON THE PERFORMANCE OF A SMALL AXIAL FLOW TURBINE

by Richard J. Roelke

National Aeronautics and Space Administration

Lewis Research Center

Cleveland, Ohio 44135

and Jeffrey E. Haas

Propulsion Laboratory

AVRADCOM Research and Technology Laboratories

Lewis Research Center

Cleveland, Ohio 44135

\section{ABSTRACT}

An experimental investigation was conducted to determine the effect of blade profile inaccuracies and surface finish on the aerodynamic performance of a $11.15 \mathrm{~cm}$ tip diameter turbine. The as-received cast rotor blades had a significantly thicker profile than the design intent and a fairly rough surface finish. Stage test results showed an increase of one point in efficiency by smoothing the surface finish and another three points by thinning the blade profiles to near the design profile. Most of the performance gain between the as-cast thick and the thinned rotor blades, both with the same surface finish, was attributed to reduced trailing edge losses of the recontoured blades. 
THE EFFECT OF ROTOR BLADE THICKNESS AND SURFACE FINISH

ON THE PERFORMANCE OF A SMALL AXIAL FLOW TURBINE

by Richard J. Roelke

National Aeronautics and Space Administration

Lewis Research Center

Cleveland, Ohio 44135

and Jeffrey E. Haas

Propulsion Laboratory

AVRADCOM Research and Technology Laboratories

Lewis Research Center

Cleveland, Ohio 44135

\section{INTRODUCTION}

The efficiency of small (under about $15 \mathrm{~cm}$ tip diameter) axial turbines has not equaled that demonstrated in larger machines. The chief reasons for this are Reynolds number effects and compromises

$\infty$ made in the aerodynamic design to accommodate $1 \mathrm{imi-}$ $\stackrel{O}{\circ}$ tations in mechanical design and fabrication pro-

'́ cesses. A practical small turbine design will almost always have a lower blade aspect ratio, higher trailing edge blockage, and a higher rotor tip clearance than a similar large turbine. Further performance degradation may also be caused by manufacturing imperfections because it is difficult to make the blade profiles with the same precision or relative surface smoothness as large turbines. The effect of these manufacturing imperfections on the performance of a small single stage turbine is the subject of this paper.

Few reports have appeared on the effect of these manufacturing imperfections in comparison to the other causes affecting the performance of small turbines. Bammert and Sandstede (1) reported on a series of cascade tests and a four stage turbine test where the surface roughness was changed and the blade profiles were either uniformly thinned or thickened to simulate manufacturing errors. Their results indicated dramatic changes in blade losses. The results of the investigation described herein are an outgrowth of the automotive gas turbine technology program conducted at the NASA-Lewis Research Center. A part of that program consisted of a series of component performance tests of the compressor-crive turbine for the Department of
Energy automotive gas turbine demonstrator engine. The engine and technology program are described in (2). The turbine blading used in the subject tests consisted of duplicates of the stator and rotor castings used in the demonstrator engine. Inspection of the blading made before the start of the turbine component tests showed significant deviations from design in the profile shape and a fairly rough surface. The initial tests were made to determine the performance of the as-cast blading. After these initial tests two subsequent turbine builds were evaluated. One build had reduced rotor blade surface roughness and in the other build the rotor blade profiles were reworked to more nearly approach the design profile.

A11 performance tests were conducted with air at a nominal inlet temperature of $320 \mathrm{~K}$ and an inlet pressure of 0.827 bars. The results reported in this paper were obtained by measuring the overall stage performance for a range of pressure ratios with the turbine operating at design speed. Rotorexit radial surveys of angle, total pressure and total temperature were taken at design equivalent values of speed and specific work. Results are presented in terms of efficiency and mass flow for each of the three turbine builds. Also included is the effect of the blading changes on the static pressures within the stage and the calculated changes in local efficiency based on the rotor-exit surveys. The results of the complete series of performance tests conducted with this turbine are reported in (3).

\section{SYMBOLS}

m

r

U

V

W

mass flow rate, $\mathrm{kg} / \mathrm{sec}$

radius, $m$

blade velocity

absolute gas velocity, $\mathrm{m} / \mathrm{sec}$

relative gas velocity, m/ sec

absolute gas angle measured from axial

direction, deg 


\section{Subscripts:}

$\begin{array}{ll}\mathrm{cr} & \text { condition corresponding to Mach number of unity } \\ \mathrm{m} & \text { blade midspan } \\ 0 & \text { station at vortex manifold inlet (Fig. 1) } \\ 1 & \text { station at stator inlet (Fig. 1) } \\ 2 & \text { station at stator exit (Fig. } 1) \\ 3 & \text { station at rotor exit (Fig. } 1)\end{array}$

\section{TURBINE DESCRIPTION}

The turbine used in this program was the NASAdesigned compressor drive turbine for the Department of Energy automotive gas turbine demonstrator engine. A cross-section of the turbine is shown in Fig. 1. Reference 4 describes the aerodynamic desion of the turbine. The turbine was designed with a tip diameter of $11.15 \mathrm{~cm}$, stator and rotor blade heights of nominally $1.12 \mathrm{~cm}$ and trailing edge thicknesses of $0.038 \mathrm{~cm}$ for both blade rows. There were 15 stator blades and 62 rotor blades. The design trailing edge blockages were nominally 4.3 and 11.8 percent for the stator and rotor respectively. The turbine was designed for a work factor (specific work/mean blade speed squared) of 2.1. The design mean section velocity diagram and blade surface velocity distributions are shown in Fig. 2 . The stator exit absolute critical velocity ratio was 0.929 and the rotor exit relative critical velocity ratio was 0.818 . Very little diffusion was predicted on either of the stator blade surfaces; however, moderate diffusion was predicted for both the pressure and suction surfaces of the rotor blade.

The turbine blading used for component testing were duplicates of the stator and rotor castings used in the engine. Inspection of the rotor blading before the start of the turbine testing showed significant deviations from design in the profile shape and a fairly rough surface. Figure 3 compares inspection tracings of the mean and tip sections with the design profile of two randomly selected rotor blades. Hub section tracings were not obtained because the tracing stylus was too large to fit in the small hub area. The inspection tracings show some waviness in the blade profiles and an increase in the blade thickness. Measurements made indicated local regions of the blade profiles fell outside the profile tolerance band by up to $0.05 \mathrm{~mm}$. The profile tolerance was $\pm 0.1 \mathrm{~mm}$. The average trailing edge thickness based on these and other inspection tracings and the hub throat measurement was $0.053 \mathrm{~cm}$ resulting in a trailing edge blockage of 16.5 percent. Surface roughness measurements were made on the pressure and suction surfaces of several blades and averaged 1.35 microns.

Surface velocity distributions were not generated for the as-cast rotor blades primarily because there was no "typical" as-cast profile. The inspection traces made showed profile variations from blade to blade. Also tracings of the hub section profile could not be obtained.

Profile tracings for the stator were not generated since the blades were cast integrally with the endwalls. However, stator throat measurements indicated that the stator flow area was undersized by 4.1 percent. The reduced flow area was caused by the size of the fillets and draft angles used in casting the stator. The as-cast stator trailing edge blockage was nominally 4.5 percent.
Turbine aerodynamic performance tests were made using the as-cast blading. After these tests were made, two modifications were made to the rotor blading. The first modification consisted of reducing the blade surface roughness. This process consisted of polishing the suction surface of each of the blades (reducing the average suction surface roughness to 0.33 microns) and applying a thin coat of lacquer to the pressure surfaces. The average pressure surface roughness was 0.95 micron resulting in an average surface roughness for the blade of 0.64 microns. Tests were then made on this configuration. The second modification consisted of electric discharge machining the rotor profiles to the design profile. The process consisted of slowly removing metal from the rotor profiles until inspection traces at the mean and tip agreed closely with the design profile. Rotor throat measurements indicated that the hub section was still thick. However, any further hub machining may have resulted in undersized profiles away from the hub, and perhaps steps in the hub endwall if the machining electrode had touched the hub. Figure 4 shows a comparison of the throat dimensions for the design, as-cast, and reworked rotor profiles, This figure shows the close agreement in the throat dimension between the design and reworked rotors, near the mean and tip sections, and the difference that remained near the hub. The average trailing edge blockage for the reworked rotor was about 13 percent. The respective suction and pressure surface roughness measurements of the reworked rotor were essentially the same as those measured after polishing and coating the as-cast rotor. Tests were then conducted using the reworked rotor blading.

\section{RESEARCH EQUIPMENT AND PROCEDURE}

The apparatus used in this investigation consisted of the research turbine, an airbrake dynamometer used to control the speed and absorb and measure the power output of the turbine, an inlet and exhaust piping system including flow controls, and appropriate instrumentation. A schematic of the experimental equipment is shown in Fig. 5 . The rotational speed of the turbine was measured with an electronic counter in conjunction with a magnetic pickup and a shaft-mounted gear. Mass flow was measured with a calibrated venturi. Turbine torque was determined by measuring the reaction torque of the airbrake which was mounted on air trunion bearings, and adding corrections for tare losses. The torque load was measured with a commercial strain-gage load cell.

The turbine instrumentation stations are shown in Figs, 1 and 6 . Instrumentation at the manifold inlet (Station 0) measured wall static pressure, total pressure, and total temperature. At both the stator inlet (Station 1) and stator exit (Station 2) static pressures were measured with six taps with three each on the inner and outer walls. The inner and outer wall taps were located opposite each other at different intervals around the circumference.

The rotor exit instrumentation station (Station 3) was located in a constant area exhaust duct approximately three axial chord lengths downstream of the rotor. This location was determined using a hot-wire anemometer survey probe so that the rotor exit instrumentation could be located at a position where the rotor wakes were mixed out. At the rotor exit static pressure, total pressure, total temperature and flow angle were mea- 
sured. The static pressure was measured with six taps with three each on the inner and outer walls. Three self-aligning probes located around the circumference were used for measurement of total pressure, total temperature, and flow angle.

For each rotor configuration data were obtained over a range of manifold inlet-to-rotor exit static pressure ratio at design equivalent speed. Data were obtained at nominal inlet flow conditions of $320 \mathrm{~K}$ and 0.827 bars. The turbine Reynolds number, $\mathrm{m} / \mu \mathrm{r}_{\mathrm{m}}$, at these conditions was about $2.44 \times 10^{5}$. The rotor tip clearance was the same for all turbine configurations tested and equaled 1.7 percent of the blade length.

For each rotor configuration a rotor exit radial survey was first conducted at design equivalent values of speed and specific work. Mass averaged values of flow angle, total temperature, and total pressure were obtained for each of the three survey locations. These mass-averaged values were then arithmetically averaged to obtain overall values. The survey probes were then positioned with one each near the tip, near midspan, and near the hub so that the average flow angle from these three positions would correspond closely to the overall mass-averaged value obtained from the survey. The radial positions of the survey probes, so determined, were not changed during the remainder of the testing of that rotor configuration. Performance data were then obtained over a range of turbine pressure ratio at design equivalent speed.

The turbine was rated on the basis of total efficiency. The actual work was calculated from torque, speed, and mass flow measurements. The ideal work was based on the manifold inlet-to-rotor exit total pressure ratio. The manifold inlet and rotor exit total pressures were calculated from mass flow, static pressure, total temperature, and flow ancle. For the calculation of manifold inlet total pressure, the flow angle was assumed to be zero.

\section{RESULTS AND DISCUSSION}

The variation in equivalent mass flow with stage total-pressure ratio at 100 percent of design speed is shown in Fig. 7. The turbine configuration with the as-cast rotor had the lowest mass flow. When the blade surface roughness of this rotor was reduced there was a slight increase in flow in the unchoked pressure ratio range but the choking flow was the same as the original rotor. The highest flow was measured with the reworked profile but the difference is small, only about 0.7 percent. The flow increase with the reworked rotor was much less than the increase in flow area of that rotor which was three percent. These results indicate, that at this rotor speed, the as-cast rotor choked before the stator but with the reworked rotor installed the stator choked first and therefore controlled the stage mass flow.

The changes in stage efficiency for the three turbine builds are shown in Fig. 8. The difference in efficiency between the as-cast and reduced roughness rotor was nominally one point and between the as-cast and reworked profile was nominally four points. These differences could be expected to increase further if it were possible to thin the rotor profile near the hub and to further smooth the surface finish of the rotor and stator blades. A probable explanation for a major portion of the increase in performance of the reworked rotor configuration is the reduced trailing edge losses. An analysis of these losses is discussed later in this paper.
The changes in wall static pressure through the turbine for the design equivalent total-to-total pressure ratio of 2.01 are shown in Fig. 9. All pressures were ratioed to the inlet total pressure at Station 0 . As the rotor blades were first smoothed and then thinned the static pressure between the stator and rotor decreased slightly. This change increased the reaction across the stator and reduced it across the rotor; however, positive rotor reaction was always maintained. It was felt that the decrease in rotor reaction was not large enough to decrease either the rotor or stage efficiency.

The rotor exit radial surveys of total temperature, total pressure, and flow angle conducted at design equivalent values of speed and specific work were used to determine radial variations in stage performance. The radial variations in turbine efficiency calculated from these survey data are shown in Fig. 10. These results show that the largest benefits of reducing the surface roughness and thinning the blade profile occurred from midspan out to the tip. This may have occurred because, as mentioned earlier, it was difficult to improve the blade surface finish and profile near the hub. With these results mass-averaged efficiencies were calculated and compared to the corresponding efficiencies shown in Fig. 8 that are based on torque measurements. In all cases the two methods of calculating the efficiencies gave values that were within 0.8 point of each other. In most comparisons the difference was only 0.1 to 0.2 point.

The rotor exit survey data together with the overall stage measurements and the results of a stator exit survey (5) were used to calculate the stage velocity diagrams for the three turbine builds at the design work condition. Selected results from those calculations are tabulated in Table I. The velocity diagram information listed in the table shows that the flow velocities generally decreased in the rotor and increased in the stator as the rotor was first smoothed and then thinned. This agrees with the trends shown in Fig. 9. Also to be noted is that the change in flow angles was not very large. In particular the rotor incidence did not change very much as the rotor configuration was changed. This indicates that the change in rotor incidence among the three turbine configurations was not a major factor contributing to the change in stage performance.

As mentioned earlier the as-cast blade profile was thicker than the design profile and therefore would have more trailing edge drag and a larger mixing loss. It was suspected that the increased trailing edge losses of the as-cast blade could account for a large portion of the performance difference between it and the reworked blade. To test this hypothesis an estimate of the effect of the rotor trailing edge thickness on rotor performance was obtained by using the Stewart mixing model (6). To this model was added a trailing edge drag suggested by Prust ( 7 ). The blade surface-friction boundary layer parameters needed in the mixing equations were obtained from a boundary layer computer code, (8), using the design mean section blade surface velocities. Rotor kinetic energy loss coefficients were calculated for three values of trailing edge thickness; design, as-cast and reworked. The trailing edge thicknesses of the as-cast and reworked blades were the averages of the hub, mean, and tip obtained from hardware measurements. The result of these calculations predicted an increase in rotor efficiency of 1.9 points due to the trail- 
ing edge difference between the as-cast and reworked blades. This change in rotor efficiency was then used in a turbine performance computer code (9) to predict the effect on the stace performance. The results of the analysis indicated an increase in stage efficiency of 2.7 points by thinning the rotor blades. The difference in efficiency shown in Fig. 8 between the reduced roughness and reworked rotors was nominally three points. Therefore, it appears that the reduction in rotor trailing edge loss was the main reason for the performance gain. An analysis procedure similar to that described above for the effect of blade trailing edge thickness was used to try to predict the effect of blade surface roughness. However, the results were inconclusive because of present limitations in the referenced boundary layer code to account for surface roughness changes.

A comparison was also made between the effect of blade surface roughness measured in this test program and the results reported in (1). According to the information in the reference a decrease in the surface roughness from 1.35 microns to 0.64 microns could result in an increase in stage efficiency of about 1.2 points. This predicted increase in efficiency is generally consistant with the increase measured during the test program. An increase of nominally one point was measured with the turbine operating at design equivalent speed and work.

\section{CONCLUDING REMARKS}

The results obtained in this experimental investigation showed that inaccuracies in the manufacture of small turbine blades can cause significant turbine performance penalties. Small dimensional deviations from design that may be acceptable in large machines must be critically examined to judge the impact in a small machine. Ultimately, analytical methods must be developed to predict these effects. For this turbine, obtaining an accurate blade profile and a smooth surface finish significantly improved its performance. Analytical predictions of these effects compared closely with the experimental results. Finally, the quality of the castings procured for this demonstrator engine program may not be indicative of what may be reasonably achieved given more time to further develop the manufacturing processes.

\section{REFERENCES}

1. Bammert, K. and Sandstede, H, "Influence of Manufacturing Tolerances and Surface Roughness of Blades on the Performance of Turbines," ASME Paper No. 75-GT-35, Mar. 1975.

2. Ball, G. A., Gumaer, J. I., and Sebestyen, T. M., "The ERDA/Chrysler Upgraded Gas Turbine Engine - Objectives and Design," SAE Paper No. $760279,1976$.

3. Roelke, R. J. and Haas, J. E., "Cold-Air Performance of Compressor-Drive Turbine of Department of Energy Upgraded Automobile Gas Turbine Engine, II - Stage Performance," (to be published).

4. Roelke, R. J. and McLallin, K. L., "The Aerodynamic Design of a Compressor-Drive Turbine for Use in a $75 \mathrm{~kW}$ Automotive Engine," NASA TM X-71717, 1975.

5. Roelke, R. J. and Haas, J. E., "Cold-Air Performance of Compressor-Drive Turbine of Department of Energy Upgraded Automobile Gas Turbine Engine, I - Volute-Manifold and Stator Performance," NASA TM-81932, 1981.

6. Stewart, W. L., "Analysis of Two-Dimensional Compressible-Flow Loss Characteristics Downstream of Turbomachine Blade Rows in Terms of Basic BoundaryLayer Characteristics," NACA TN-3515, 1955.

7. Prust, H. W., Jr., "Boundary Layer Losses," Turbine Design and Application, Vol. II, NASA SP-290, 1973, pp. 93-124.

8. MCNally, W. D., "FORTRAN Program for Calculating Compressible Laminar and Turbulent Boundary Layers in Arbitrary Pressure Gradients," NASA TN D-5681, 1970.

9. Flagg, E. E., "Analytical Procedure and Computer Program for Determining the Off-Design Performance of Axial Flow Machines, " NASA CR-710, 1967.

TABLE 1. - CALCULATEO STAGE VELOCITY DIAGRAMS AT DESIGN WORK FACTOR

\begin{tabular}{|c|c|c|c|c|c|c|c|c|c|c|c|c|c|c|c|c|}
\hline \multirow[b]{2}{*}{$\begin{array}{l}\text { Percent span } \\
\text { (hub is zero) }\end{array}$} & \multirow{2}{*}{$\frac{\text { Desion }}{50}$} & \multicolumn{5}{|c|}{ As-cast } & \multicolumn{5}{|c|}{ Reduced rouchress } & \multicolumn{5}{|c|}{ Reworked } \\
\hline & & 5 & 25 & 50 & 75 & of & 5 & 25 & 50 & 75 & 95 & 5 & 25 & 50 & 75 & 95 \\
\hline $\begin{array}{l}\text { Station ? } \\
\text { Absolute velocity } \\
\text { ratic }\end{array}$ & 0.920 & 0.045 & 0.809 & $0.86^{\circ}$ & 0.841 & 0.808 & 1.000 & 0.920 & 0.873 & 0.863 & 0.752 & 1.002 & 0.937 & 0.923 & 0.897 & 0.793 \\
\hline $\begin{array}{l}\text { Relative velocity } \\
\text { ratio }\end{array}$ & .559 & .632 & .551 & .405 & .064 & .450 & .691 & .573 & .500 & .487 & .402 & .694 & .592 & .553 & .522 & .437 \\
\hline $\begin{array}{l}\text { Relative flow } \\
\text { anole, deg }\end{array}$ & $\Delta 5.8$ & 44.7 & 47.6 & 46.0 & 38.0 & 27.5 & 46.3 & 48.4 & 46.3 & 39.4 & 23.0 & 46.4 & 49.1 & 48.4 & 41.3 & 26. \\
\hline $\begin{array}{l}\text { Rotor incidence, } \\
\text { dea }\end{array}$ & 0.1 & -4.3 & -0.2 & 0.3 & -4.6 & -11.5 & -2.7 & 0.6 & 0.6 & -3.2 & -16.0 & -2.6 & 1.3 & 2.7 & $-1 \cdot 3$ & -12.3 \\
\hline $\begin{array}{l}\text { Station } 3 \\
\text { Ahsolute velocity } \\
\text { ratio }\end{array}$ & 0.521 & 0.524 & 0.593 & 0.570 & 0.520 & $0.4 f 6$ & 0.508 & 0.562 & 0.555 & 0.507 & 0.493 & 0.507 & 0.539 & 0.504 & 0.499 & 0.463 \\
\hline $\begin{array}{l}\text { Relative velecity } \\
\text { ratic }\end{array}$ & .818 & .808 & .862 & .845 & .832 & .815 & .780 & .830 & .830 & .818 & .861 & .773 & .805 & .785 & .806 & .841 \\
\hline $\begin{array}{l}\text { Absolute flow } \\
\text { angle, deg }\end{array}$ & -21.1 & -27.6 & -23.1 & -10.2 & -20.4 & -22.1 & -23.9 & -21.6 & -18.5 & -19.5 & -28.8 & -22.7 & -20.3 & -17.5 & -18.3 & -20.6 \\
\hline
\end{tabular}


TABLE I. - CALCULATED StAGE VELOCITY DIAGRAMS AT DESIGN WORK FACTOR

\begin{tabular}{|c|c|c|c|c|c|c|c|c|c|c|c|c|c|c|c|c|}
\hline \multirow[b]{2}{*}{$\begin{array}{l}\text { Percent span } \\
\text { (hub is zero) }\end{array}$} & \multirow{2}{*}{\begin{tabular}{|c|} 
Design \\
50
\end{tabular}} & \multicolumn{5}{|c|}{ As-cast } & \multicolumn{5}{|c|}{ Reduced rouohness } & \multicolumn{5}{|c|}{ Reworked } \\
\hline & & 5 & 25 & 50 & 75 & 95 & 5 & 25 & 50 & 75 & 95 & 5 & 25 & 50 & 75 & 95 \\
\hline $\begin{array}{l}\text { Station } 2 \\
\text { Absolute velocity } \\
\text { ratio }\end{array}$ & 0.929 & 0.945 & 0.899 & 0.869 & $0.84]$ & 0.808 & 1.000 & 0.920 & 0.873 & 0.863 & 0.752 & 1.002 & 0.937 & 0.923 & 0.897 & 0.793 \\
\hline $\begin{array}{l}\text { Relative velocity } \\
\text { ratio }\end{array}$ & .559 & .632 & .551 & .495 & .464 & .450 & .691 & .573 & .500 & .487 & .402 & .694 & .592 & .553 & .522 & .437 \\
\hline $\begin{array}{l}\text { Relative flow } \\
\text { angle, dea }\end{array}$ & $\Delta 5.8$ & 44.7 & 47.6 & 46.0 & 38.0 & 27.5 & 46.3 & 48.4 & 46.3 & 39.4 & 23.0 & 46.4 & 49.1 & 48.4 & 41.3 & 26.7 \\
\hline $\begin{array}{l}\text { Rotor incidence, } \\
\text { deg }\end{array}$ & 0.1 & -4.3 & -0.2 & 0.3 & -4.6 & -11.5 & -2.7 & 0.6 & 0.6 & -3.2 & -16.0 & -2.6 & 1.3 & 2.7 & -1.3 & -12.3 \\
\hline $\begin{array}{l}\text { Station } 3 \\
\text { Absolute velocity } \\
\text { ratio }\end{array}$ & $0.52]$ & 0.524 & 0.593 & 0.570 & 0.520 & 0.466 & 0.508 & 0.562 & 0.555 & 0.507 & 0.493 & 0.507 & 0.539 & 0.504 & 0.499 & 0.463 \\
\hline $\begin{array}{l}\text { Relative velocity } \\
\text { ratio }\end{array}$ & .818 & .808 & .862 & .845 & .832 & .815 & .780 & .830 & .830 & .818 & .861 & .773 & .805 & .785 & .806 & .841 \\
\hline $\begin{array}{c}\text { Absolute flow } \\
\text { angle, deg }\end{array}$ & -21.1 & -27.6 & -23.1 & -19.2 & -20.4 & -22.1 & -23.9 & -21.6 & -18.5 & -19.5 & -28.8 & -22.7 & -20.3 & -17.5 & -18.3 & -29.6 \\
\hline
\end{tabular}




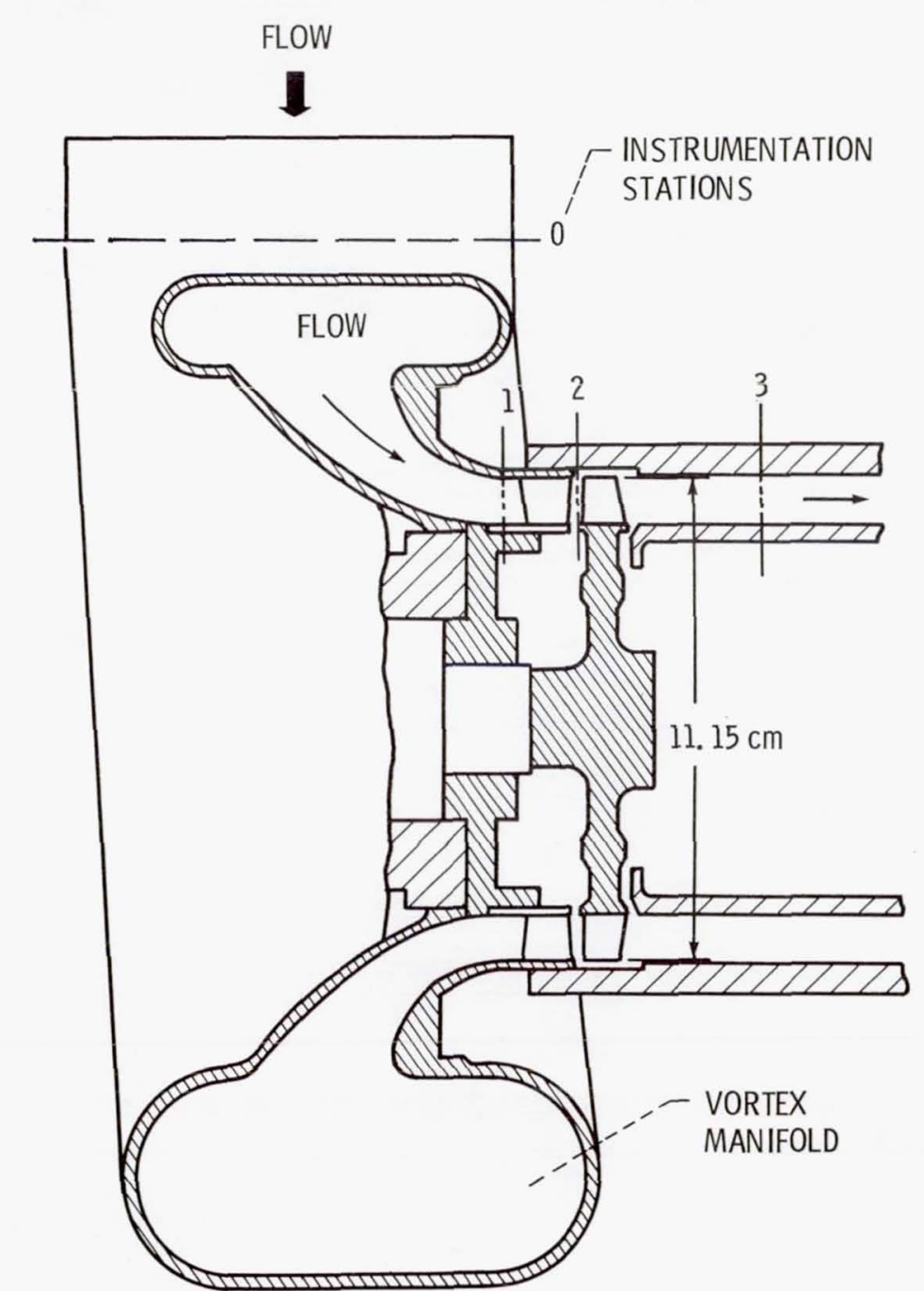

Figure 1. - Cross-sectional schematic of turbine.

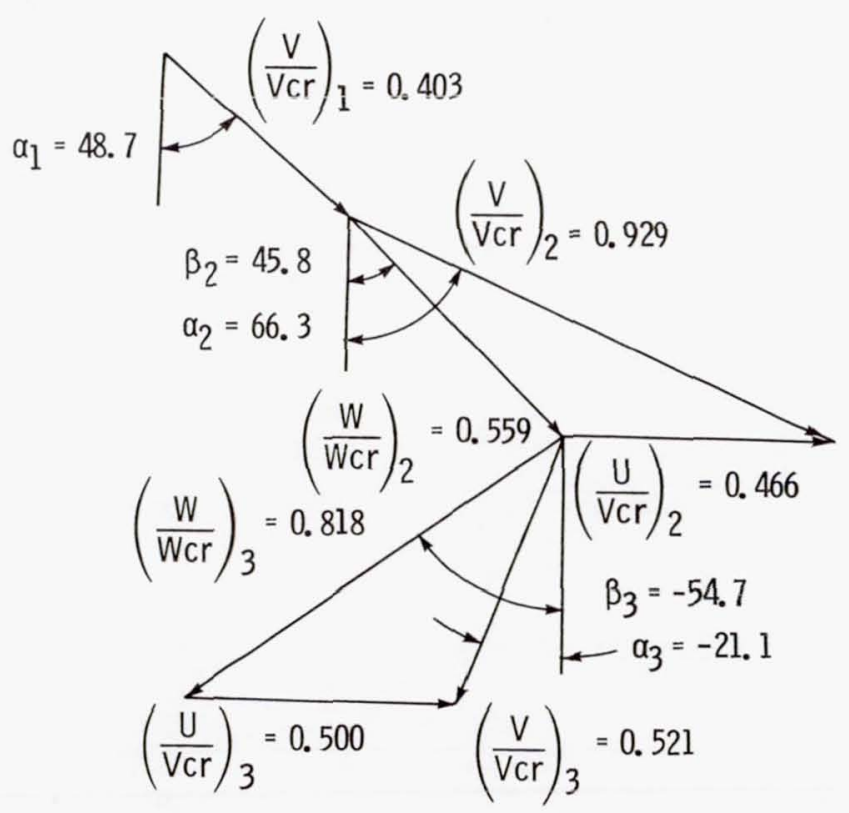

(a) VELOCITY DIAGRAM.

Figure 2. - Design mean section velocity diagram and blade surface velocity distributions. 

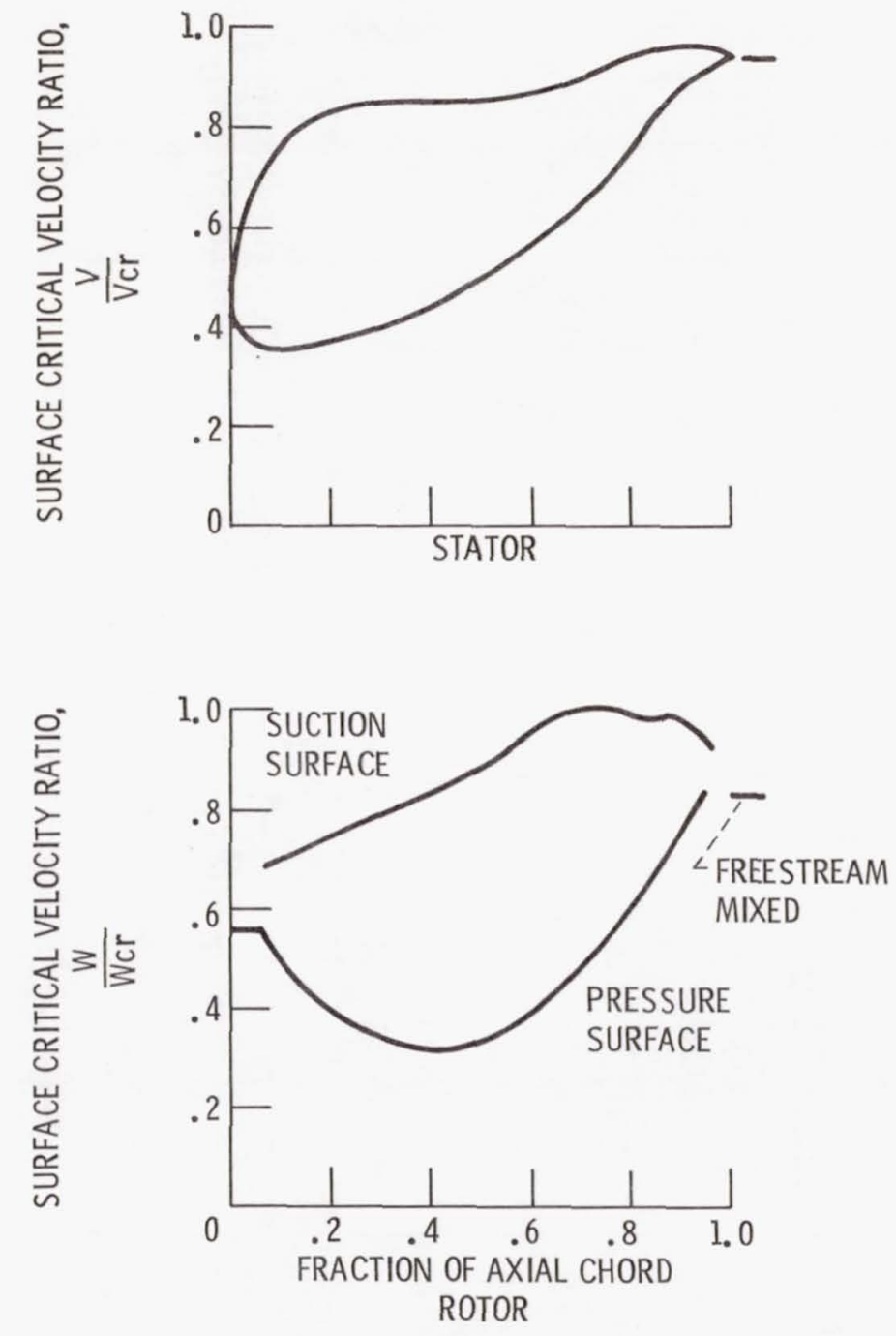

(b) SURFACE VELOCITY.

Figure 2 - Concluded.
INSPECTION TRACE

DESIGN PROFIE

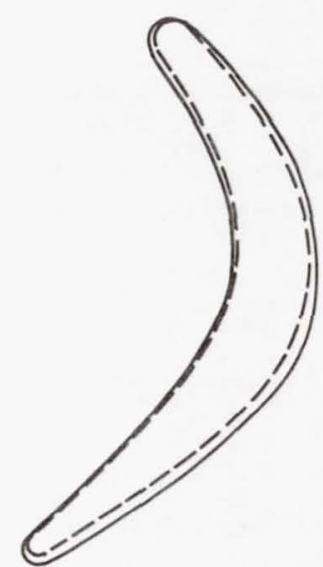

BLADE NO. 1

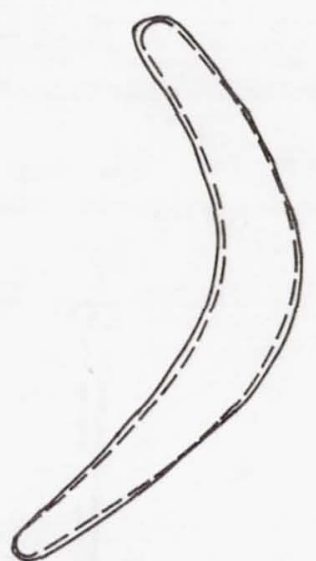

BLADE NO. 2 (a) TIP SECTIONS.
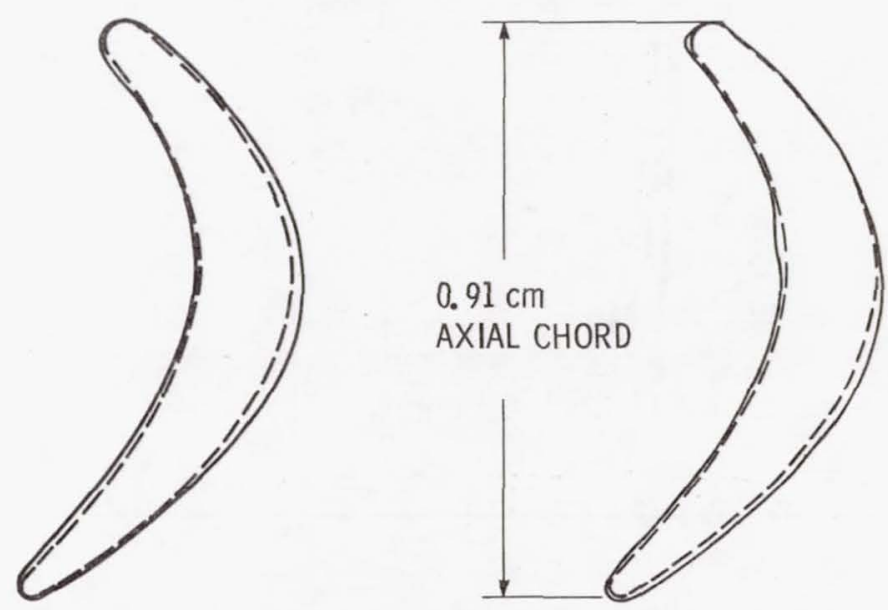

(b) MEAN SECTIONS.

Figure 3. - Comparison of design and as-cast rotor blade profiles. 


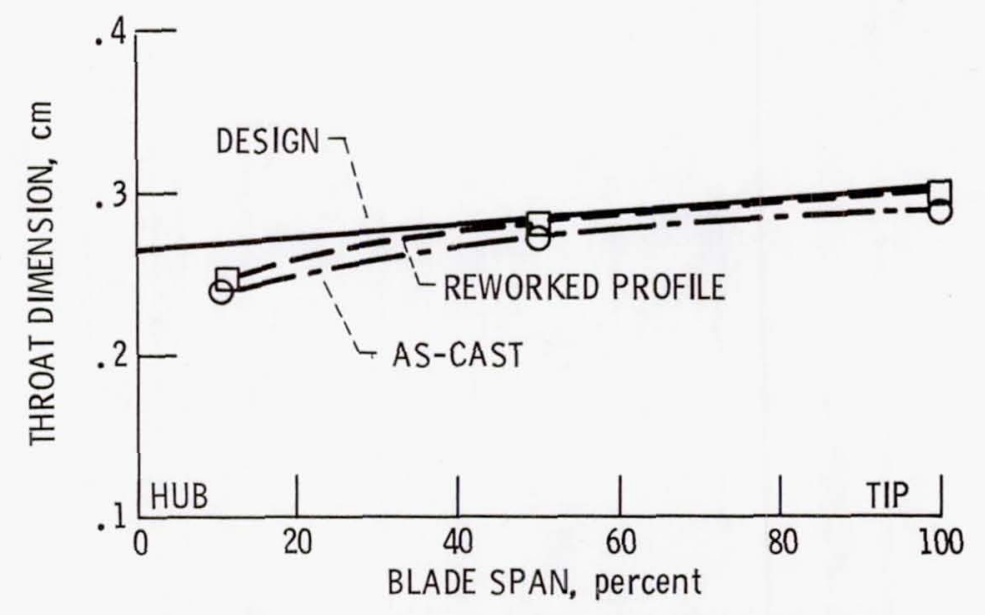

Figure 4. - Radial variation in rotor throat dimension.

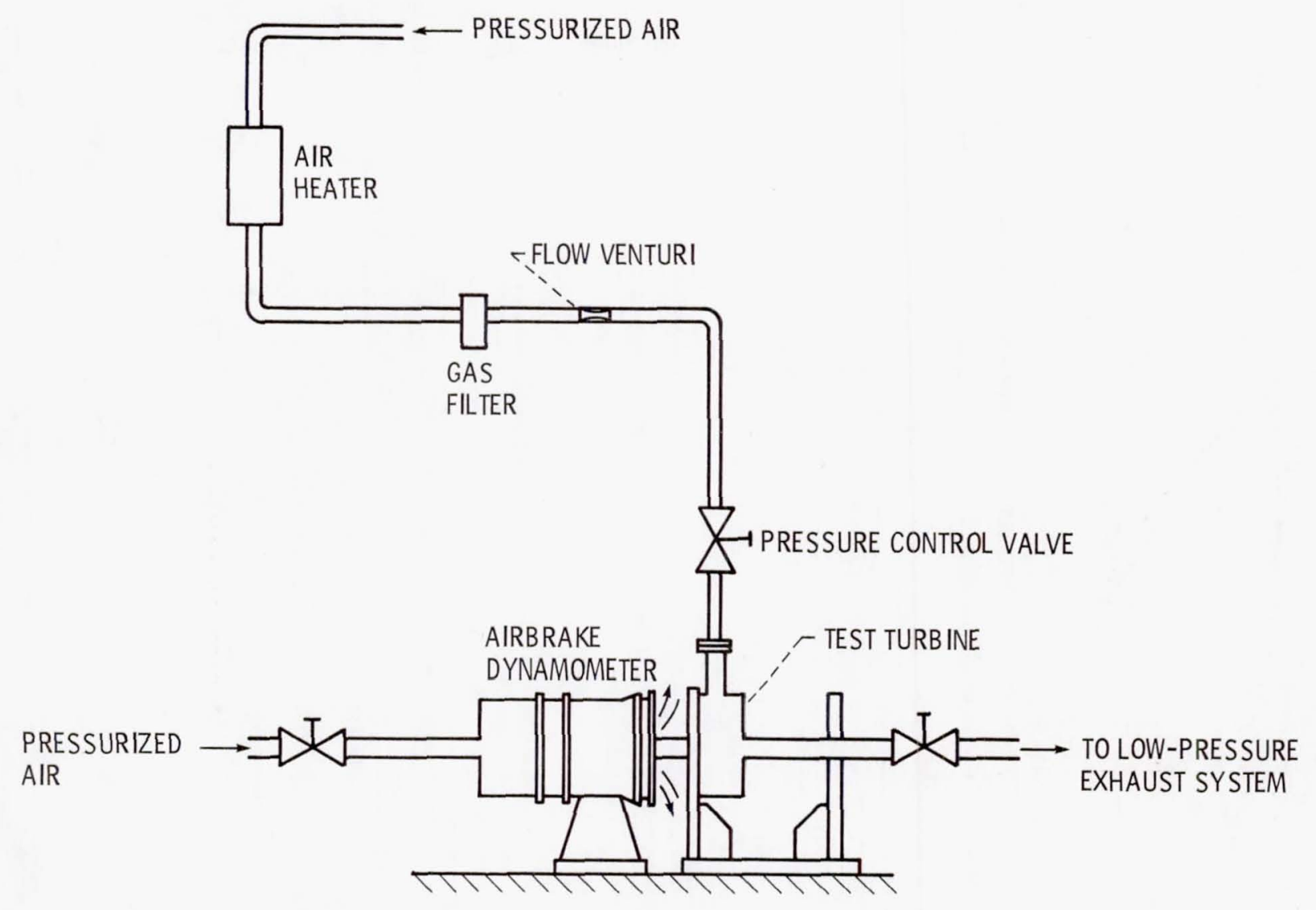

Figure 5. - Test installation schematic. 
INSTRUMENTATION

- STATIC PRESSURE

- TOTAL PRESSURE

$\times$ TOTAL TEMPERATURE

$\ominus$ TOTAL PRESSURE - FLOW ANGLE

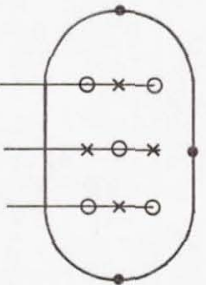

MANIFOLD INLET (STATION 0)

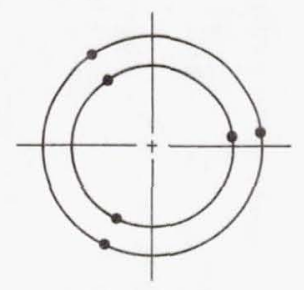

STATOR EXIT (STATION 2)

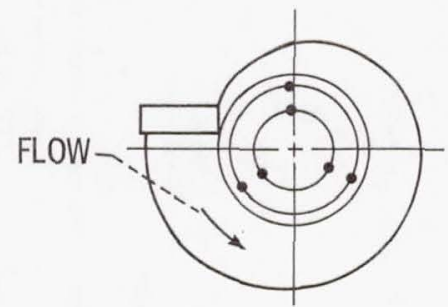

STATOR INLET (STATION 1)

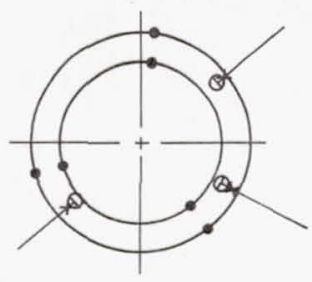

ROTOR EXIT (STATION 3)
Figure 6. - Flow path instrumentation, viewed looking downstream.

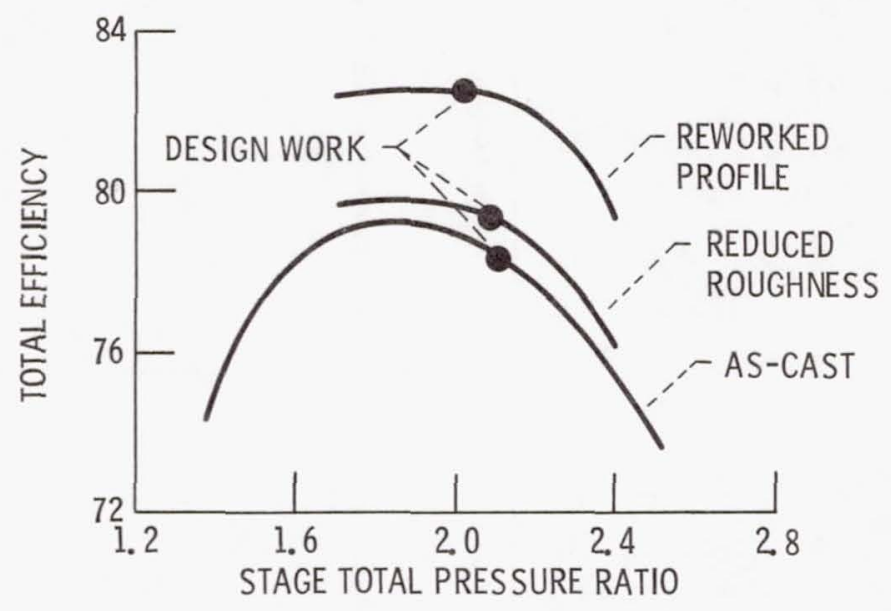

Figure 8. - Variation of efficiency with pressure ratio at design speed.

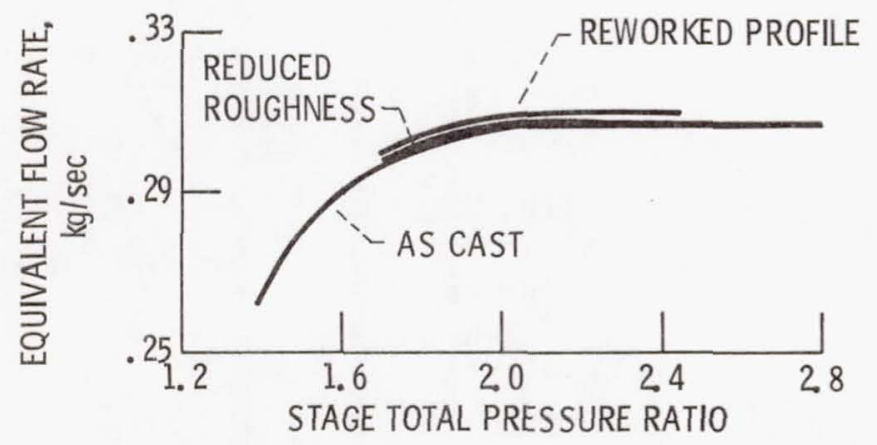

Figure 7. - Variation of equivalent mass flow with pressure ratio at design speed. 


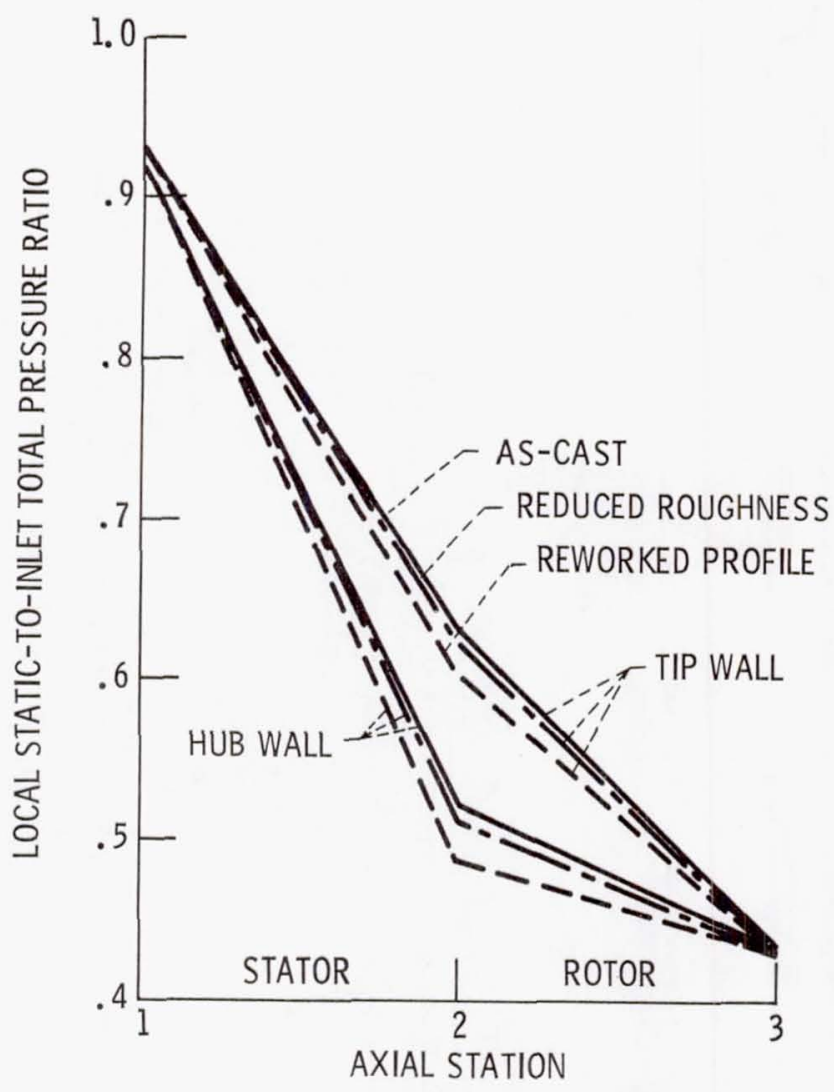

Figure 9. - Variation of static pressure with axial location at design speed and stage total pressure ratio.

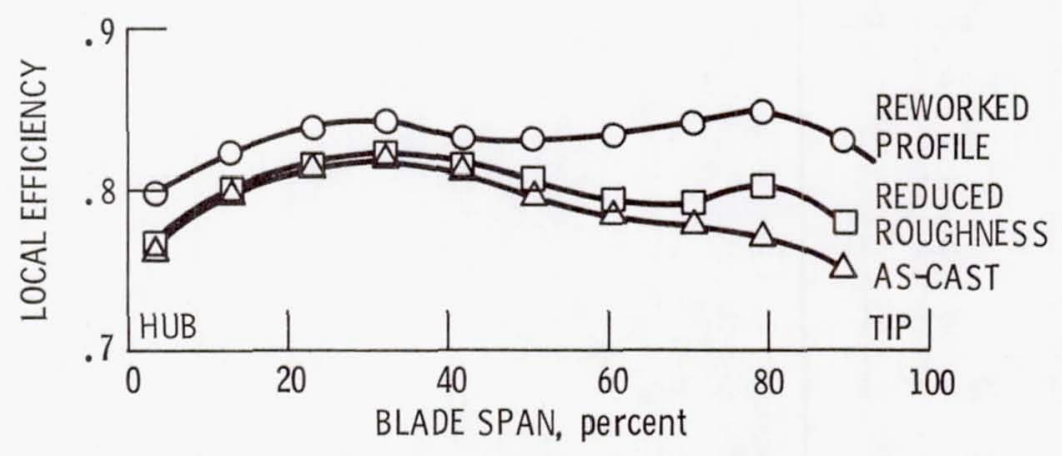

Figure 10. - Radial variation in efficiency at design speed and work. 


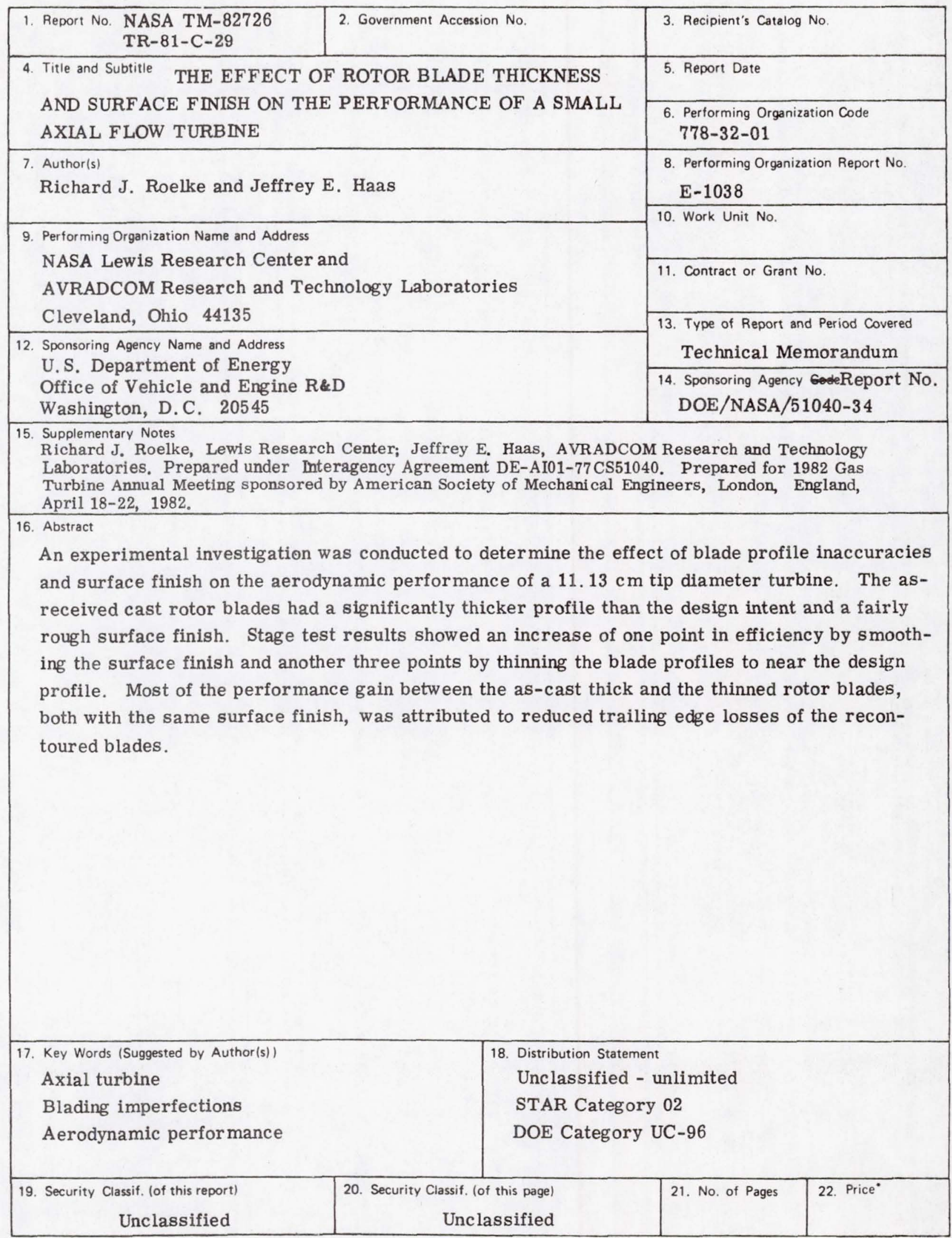

* For sale by the National Technical Information Service, Springfield, Virginia 22161 
